\title{
The Impact of the National Institute for Pharmaceutical Technology and Education on Academic Research
}

\author{
Marilyn K. Speedie ${ }^{1,2}$ (I)
}

Received 23 April 2018; accepted 16 May 2018; published online 24 August 2018

\begin{abstract}
Surveys of institutional representatives of member institutions and faculty members engaged in the National Institute for Pharmaceutical Technology and Education (NIPTE) revealed that NIPTE is having a positive impact on academic research in the area of pharmaceutical technology by aligning research directions with FDA needs, by providing funding that may not be available elsewhere, and by creating a collegial and collaborative relationship among researchers in this area from various institutions. NIPTE is contributing to the viability of pharmaceutics and pharmaceutical engineering research in academic settings. Some responders cite the fluctuations in funding and relative low levels of funding received as a problem in maintaining programs, but most perceived a positive impact.
\end{abstract}

KEY WORDS: team science; collaboration; research outcomes; pharmaceutical technology; manufacturing science.

The National Institute for Pharmaceutical Technology and Research (NIPTE) is a multi-university partnership, incorporated in 2007 as an independent institute with institutional members that represent (currently) seventeen academic universities (Table I). A description of similar multi-university partnerships and the founding of NIPTE has been published previously (1)). Most of these institutions are located in the Midwest but extend as far east as Puerto Rico, Connecticut, and Maryland and as far south as Texas. Each of these member institutions had a program (department or graduate program or group of researchers) working in the field of Pharmaceutics or Pharmaceutical Engineering, and research focused on aspects of drug formulation, physical pharmacy, and engineering. Prior to NIPTE's formation, each of the programs had 1-4 faculty members working in related areas and received the majority of their research funding from industrial contracts. Partly due to the emphasis on NIH funding in many colleges of pharmacy, the field of physical pharmacy or pharmaceutics had fallen out of favor for faculty hiring and many schools and colleges of pharmacy did not have any faculty members working in

Communicated by: Ajaz S. Hussain, Kenneth Morris, and Vadim J. Gurvich

\footnotetext{
${ }^{1}$ Department of Medicinal Chemistry, University of Minnesota College of Pharmacy, 717 Delaware St., room 484, Minneapolis, Minnesota 55455, USA.

${ }^{2}$ To whom correspondence should be addressed. (e-mail: Speed001@umn.edu)
}

this area. That, of course, meant that the production of Ph.D.s in this discipline also was declining.

At the same time, the need for new knowledge in this discipline was expanding. With increased focus on translational science and getting pharmaceutical products from bench to bedside, industrial research and development was faced with increased challenges in both productivity and quality that limited the development of new products for use in humans. Also, the shift to use of a higher percentage of generic products meant that needs for understanding the physical and formulation challenges for a given chemical entity were expanded. Industry was frustrated, as was the FDA and academic researchers, by the model of industrial contracts yielding proprietary knowledge, because fundamental discoveries and principles were not being broadly disseminated and shared across industries. It seemed that the landscape was right for a collaborative effort to expand public sector research efforts in this discipline.

The goals, then, of the National Institute of Pharmaceutical Technology and Education were (1) to benefit manufacturing quality and productivity by generating new and disseminated knowledge about the physical aspects of formulation and drug manufacturing; (2) to work with the FDA and other agencies to identify important areas of need for new knowledge; (3) to gain and distribute funding to researchers to do the research necessary to answer the pressing questions of the discipline; (4) to maintain the presence (and hiring) of faculty in the discipline in schools and colleges of pharmacy and in engineering programs; (4) to provide for multi-institutional collaboration to share 
Table I. Membership of the National Institute of Pharmaceutical Technology and Education

\begin{tabular}{|c|c|c|}
\hline Institution & Unit (School, college, or department) & Year joined \\
\hline Duquesne University & School of Pharmacy & 2007 \\
\hline Illinois Institute of Technology & Armour College of Engineering & 2007 \\
\hline Long Island University & Arnold \& Marie Schwartz College of Pharmacy and Health Sciences & 2016 \\
\hline Purdue University & College of Pharmacy, School of Chemical Engineering & 2007 \\
\hline Rutgers University & Ernest Mario School of Pharmacy, School of Engineering & 2007 \\
\hline Texas A\&M & Irma Rangel College of Pharmacy & 2017 \\
\hline University of Connecticut & School of Pharmacy & 2007 \\
\hline University of Iowa & College of Pharmacy & 2007 \\
\hline University of Kansas & School of Pharmacy & 2007, 2013 \\
\hline University of Kentucky & College of Pharmacy & 2007 \\
\hline University of Maryland, Baltimore & School of Pharmacy & 2007 \\
\hline University of Michigan & College of Pharmacy & 2011 \\
\hline University of Minnesota & College of Pharmacy & 2007 \\
\hline University of Puerto Rico & School of Pharmacy & 2007 \\
\hline University of Rochester & Medical Center & 2015 \\
\hline University of Texas at Austin & College of Pharmacy & 2016 \\
\hline University of Wisconsin & School of Pharmacy & 2011 \\
\hline
\end{tabular}

knowledge and expertise and research resources and infrastructure; (5) to create a critical mass of investigators working in the discipline and provide funding for their research; (6) to support the development and education of graduate students in this field and to support the development of junior faculty so they could thrive in an academic environment; and (7) to provide experts to educate industrial and FDA scientists in the specialty areas of the discipline.

Now, eleven years later, it is appropriate to assess our success in meeting our goals. Since NIPTE continues to exist, in part, because administrators of the programs see sufficient value in the Institute to justify paying the membership fees (\$15,000 per annum) and because faculty researchers continue to apply and receive funding for research, it seemed that a survey of administrators and faculty members would yield useful information. We asked questions about the outcomes of the funding, but also requested general comments about NIPTE's role in promoting the discipline of manufacturing science aside from funding considerations. Surveys were distributed via email to individuals who are currently serving or have served in the past as the administrative representative to the Board of Directors. Completion of another survey was requested of faculty members at the same institutions although the responses were received sometimes from faculty and administrators at the same institution and sometimes one or the other. The survey asked for perceptions and opinions, not data. The two surveys are shown in Table II.

As background, it is useful to note that grant funding and faculty participation in NIPTE projects varies widely across the seventeen institutions. This is to be expected because the

Table II. Survey Questionnaires

For Institutional Representatives:

1. My institution has received NIPTE funding for research and/or education

a. Minimally

b. Less than half the years NIPTE has been in existence

c. More than half the years NIPTE has been in existence

Please comment.

2. NIPTE has strengthened the Pharmaceutics or Pharmaceutical Manufacturing research program within my institution? (yes or no, please explain).

3. Overall, NIPTE funding has strengthened graduate training in pharmaceutical manufacturing in my institution (yes or no, please explain).

4. NIPTE has helped junior faculty get their research program established (yes or no, please explain).

For NIPTE Faculty:

1. I have received NIPTE funding for my research? (yes or no)

2. I have received NIPTE funding for an educational program? (yes or no)

3. What has been the impact of that funding?

a. Research program has not expanded-NIPTE funding just replaced funding from other sources

b. Research program has expanded with NIPTE funding - to what extent? ("somewhat" to "major expansion"?)

c. Research program accommodated NIPTE project for time of project but has stayed the same size and scope.

d. Other, please explain.

4. Have you expanded the number of trainees you have educated because of NIPTE funding? 
topics of the requests for proposals are determined largely by the needs of the largest funder, the FDA, and, while proposals are faculty generated and competitive, not all faculty members' areas of expertise and research align with the current needs of the FDA. Occasionally, teams are assembled with coordination by the faculty committee or NIPTE administration to respond to FDA requests, but team members are recruited by expertise and not home institution. Table III illustrates the distribution of funding received by the various member institutions. Some institutions are quite new to the organization, which accounts for some of the disparity in funding received. In only a few cases did the lower amount of funding to a given institution result in less enthusiasm for NIPTE membership, which speaks to the value perceived in membership in addition to funding of research.

Responses were received from ten institutional administrative representatives and eight faculty participants, all of whom had received NIPTE funding at some point. Of the ten administrative responses, four have received funding more than half the years NIPTE has been in existence and describe funding as "consistent," three are new members within the past three years and have had funding since joining and, three felt funding had been minimal and inconsistent. One of the latter institutions had dropped out and rejoined as new opportunities surfaced. Seven of the ten felt that NIPTE has been important in strengthening the discipline of pharmaceutical manufacturing within their institution with comments, such as "instrumental to strengthening funding that was not available from federal agencies or pharmaceutical manufacturers" and "collaborations within NIPTE have been very productive." Three others said either that NIPTE represented minimal funding levels compared to other sources of funding for the discipline or that the inconsistency of funding limited the impact of NIPTE upon their programs. Respondents were split (five to five) on the impact on graduate training with comments, such as "inter-institutional cooperation had a positive impact on both faculty and graduate students" and "research funding was used to support graduate students," contrasted with more negative comments, such as "the enthusiasm to develop a program was hampered by fluctuations in funding." Finally, in response to the question about helping junior faculty, four respondents cited instances where NIPTE funding was "very important" or "critical" to the success of a funded junior investigator, while others responded that most of the NIPTE funding went to mid-level or senior investigators.

Responses were received from eight participating faculty members, all of whom had received NIPTE funding for research and four of the eight had received NIPTE funding for educational efforts as well. All but two spoke of expanded research efforts in areas, such as co-crystals, biosimilars, and polymer characterization, and offered comments, such as "very significant to our growth" and "became competitive for other FDA-based funding." Five of the eight had added graduate trainees because of the funding.

On the issue of building and promoting collaborative teams (aside from funding) in the manufacturing/ pharmaceutical technology sciences, comments were received, such as "with NIPTE we have created a vibrant community of scientists who are actively collaborating even outside the NIPTE funding mechanism" and "we believe our association with NIPTE will strengthen and advance our research enterprise and graduate training programs." Another said that they joined "out of a sense of the greater good...putting our shoulders together to not allow [the study of] pharmaceutical manufacturing to dissolve."

Overall, it appears NIPTE has played three important roles and is meeting its goals. First of all, it has provided a mechanism to align research in the fields of pharmaceutics, pharmaceutical manufacturing, pharmaceutical engineering, and physical pharmacy (collectively called "pharmaceutical technology") with the needs of the FDA so that this discipline had a source of funding for the research they wish to do. The FDA provides an alternative funding mechanism to industry contracts, which often yield proprietary results, and NIH and NSF, federal funding sources whose priorities often do not

Table III. Funding Received 2011-2017 by NIPTE Institutions (institutions deidentified). Data from Reference (2)

\begin{tabular}{lll}
\hline Institution \# (ranked) & Total amount of funding received & \% of total \\
\hline 1 & $\$ 3,437,357$ & 29 \\
2 & $\$ 1,524,222$ & 13 \\
3 & $\$ 890,878$ & 8 \\
4 & $\$ 823,173$ & 7 \\
5 & $\$ 755,134$ & 6 \\
6 & $\$ 621,113$ & 5 \\
7 & $\$ 592,545$ & 5 \\
8 & $\$ 440,794$ & 4 \\
9 & $\$ 297,700$ & 3 \\
10 & $\$ 262,847$ & 2 \\
11 & $\$ 223,700$ & 2 \\
12 & $\$ 217,200$ & 2 \\
13 & $\$ 177,460$ & 2 \\
14 & $\$ 100,000$ & 1 \\
15 & $\$ 55,000$ & $<1$ \\
16 & 0 & 0 \\
\hline
\end{tabular}


include these areas of research. Funding facilitates research and graduate training but also keeps the discipline viable in Colleges and Schools of Pharmacy and Engineering, where the viability of the basic science disciplines depends to some degree upon their ability to garner external funding. Secondly, NIPTE has created a sense of community among the pharmaceutical technology faculty across the various schools. Research resources have been shared and teams have been assembled to tackle larger projects than could be accomplished previously. The third important role (and perhaps the most important, but not the subject of this paper) is creating the outcomes of the research that has been performed and their impact on the efficiency and quality of manufacturing of pharmaceuticals and on the ability of the FDA to do their job in the development of new pharmaceuticals and the protection of human health.

\section{REFERENCES}

1. Gurvich VJ, Byrn SR. NIPTE: a multi-university partnership supporting academic drug development. Drug Discov Today. 2013;18:916-21.

2. Bricker, J.D., Gurvich, V.J. Finance and Audit Committee Report, presented at the NIPTE Board of Directors meeting, Corpus Christi, Texas, January 26, 2018. 